\title{
Distribution of $\mathbf{N}$-Methyl-D-aspartate-sensitive $L-\left[{ }^{3} \mathrm{H}\right]$ Glutamate- binding Sites in Rat Brain ${ }^{1}$
}

\author{
DANIEL T. MONAGHAN ${ }^{2}$ AND CARL $W$. COTMAN \\ Department of Psychobiology, University of California, Irvine, Irvine, Califonia 92717
}

\begin{abstract}
$\mathbf{N}$-methyl-D-aspartate (NMDA) is an acidic amino acid which depolarizes neurons by selectively interacting with a distinct class of excitatory amino acid receptor. Recent evidence has indicated that this receptor is a neurotransmitter receptor in the spinal cord, cerebral cortex, and hippocampus for which the endogenous ligand is likely to be L-glutamate or a structurally related compound. Using quantitative autoradiography, we have studied the anatomical distribution of the class of $\mathrm{L}-\left[{ }^{3} \mathrm{H}\right]$ glutamate-binding sites displaced by NMDA, which appear to correspond to NMDA receptors. The CA1 region of the hippocampus contains the highest density of sites. In general, telencephalic regions have high levels of binding sites. The cerebral cortex shows significant density variations among the differing layers and regions, with the highest levels found in the frontal cortex layers I to III. Within the basal ganglia, the highest levels are found in the nucleus accumbens, intermediate levels are found in the caudate/ putamen, and very low levels are found in the globus pallidus. Thalamic regions have moderate levels with variations among differing regions. Midbrain and brainstem have low levels of binding sites, but within these regions there are structures exhibiting higher levels, e.g., the nucleus of the solitary tract and the inferior olive. The distribution of NMDA sites is consistent with most, but not all, of the regions previously proposed to use glutamate as an excitatory transmitter. Thus, the distribution of NMDA-sensitive $L-\left[{ }^{3} \mathrm{H}\right]$ glutamate-binding sites suggests that the NMDA receptor represents a major, distinct subset of excitatory amino acid receptors and indicates regions in which neurotransmission may be mediated or modulated by this receptor.
\end{abstract}

Evidence from a variety of experimental approaches suggests that the excitatory amino acid L-glutamate (and possibly related compounds) is a major neurotransmitter in the vertebrate CNS (Cotman et al., 1981; Watkins and Evans, 1981; Fagg and Foster, 1983; Fonnum, 1984). Excitatory amino acid depolarizations appear to be mediated by at least three distinct receptor types which are characterized by selective interaction with $N$-methyl-D-aspartate (NMDA), quisqualate (QA), and kainate (KA) (McLennan, 1981; Watkins and Evans, 1981; and Foster and Fagg, 1984).

There is now compelling evidence that the receptor recognized

Received December 10, 1984; Revised March 12, 1985; Accepted March 15, 1985

\footnotetext{
1 This work was supported by Army Research Office Grant DAAG 29-82. K-0194 and National Institutes of Health Grant RRO 1192 (densitometry equipment). We wish to thank Deborah Yao for excellent technical assistance, Alan $\mathrm{H}$. Ganong for comments on the manuscript, and Gwen Ivy for assistance with the cortical anatomy.

${ }^{2}$ To whom correspondence should be addressed
}

by NMDA is involved in synaptic transmission. The dorsal rootevoked ventral root polysynaptic response in several vertebrate spinal cord preparations is antagonized by the appropriate spectrum of NMDA antagonists (Davies and Watkins, 1983). The generation of long term potentiation in the Schaffer collateral pathway of the hippocampus is also antagonized by specific NMDA antagonists (Collingridge et al., 1983; Harris et al., 1984; Wigstrom and Gustafsson, 1984). It has also been recently reported that, under certain conditions, EPSP and population spike responses within the hippocampus and cerebral cortex can be blocked by NMDA antagonists (Hablitz and Langmoen, 1984; Coan and Collingridge, 1985; Thomson et al., 1985). Thus, although it remains for further electrophysiological investigation to specifically define the physiological role of NMDA receptors, it is well established that these receptors are involved in mediating some aspect of synaptic transmission. Thus, localization of the binding sites for NMDA also provides independent evidence for excitatory amino acid-mediated neurotransmission in the indicated regions. In addition, since it has been shown that seizure activity induced by a variety of agents (Croucher et al., 1982; Meldrum et al., 1983a, b) can be blocked by NMDA antagonists, the localization of NMDA sites may suggest regions where this potentially therapeutic action may occur.

In a previous report (Monaghan et al., 1983a) we have described a unique binding site for $\mathrm{L}-\left[{ }^{3} \mathrm{H}\right]$ glutamate which preferentially recognizes NMDA and exhibits the characteristic NMDA receptor pharmacology. We have also recently studied this binding site in membrane preparations (Yao et al., 1984) and found the pharmacological profile to be indicative of the NMDA receptor, as had been suggested by Fagg et al. (1983). This binding site is enriched in synaptic plasma membranes and is further enriched in synaptic junctions. Fagg and Matus (1984) have recently reported that these sites are preferentially localized in isolated postsynaptic densities. The NMDA receptor identity of this binding site appears to be confirmed by the recent work of Olverman et al. (1984), who found L-glutamate to have a high affinity for $\mathrm{D}-\left[{ }^{3} \mathrm{H}\right]-2$-amino-5-phosphonopentanoate $\left(\mathrm{D}-\left[{ }^{3} \mathrm{H}\right] \mathrm{AP} 5\right.$, a selective NMDA antagonist)-binding sites with an affinity similar to that found for glutamate binding to NMDA-sensitive $\mathrm{L}-\left[{ }^{3} \mathrm{H}\right]$ glutamatebinding sites. Likewise, D- $\left[{ }^{3} \mathrm{H}\right] \mathrm{AP} 5$ exhibits a similar pharmacological specificity, a similar binding site density $\left(B_{\max }\right)$, and a similar distribution within the CNS. For both ligands, highest binding levels are found within the hippocampus, and they display identical distributions within this structure (Monaghan et al., 1983a, 1984b).

The results of this study demonstrate that NMDA-binding sites exhibit a high degree of anatomical specificity. In general, their distribution agrees with the regions proposed to use glutamate for neurotransmission, suggesting that these sites represent a major subset of excitatory amino acid receptors. Preliminary results of this study have been presented in abstract form (Yao et al., 1984).

\section{Materials and Methods}

Sprague-Dawley rats (150 to $300 \mathrm{gm}$ ) were decapitated, and the brains were rapidly removed and frozen on powdered dry ice. Tissue sections were 
prepared for autoradiography as previously described (Monaghan et al., 1983a). Briefly, 6- $\mu \mathrm{m}$ tissue sections were thaw-mounted onto acid-washed microscope slides and then immediately placed into 0 to $2^{\circ} \mathrm{C} 50 \mathrm{~mm}$ Trisacetate buffer, $\mathrm{pH} \mathrm{7.2,} \mathrm{for} 2 \mathrm{hr}$ to promote tissue adherence. Slides were then preincubated at $30^{\circ} \mathrm{C}$ for $10 \mathrm{~min}$ to further remove ondogonous gluta mate and various ions. This $30^{\circ} \mathrm{C}$ preincubation resulted in a 2- to 4 -fold increase in the specific binding levels. Inclusion of a second $30^{\circ} \mathrm{C} / 10-\mathrm{min}$ preincubation with fresh buffer did not further increase glulamale binding. The tissue sections for anatomical studies were incubated for $10 \mathrm{~min}$ at 0 to $4^{\circ} \mathrm{C}$ in $1.8 \mathrm{ml}$ of $50 \mathrm{~mm}$ Tris-acetate buffer, $\mathrm{pH} 7.2$, containing $100 \mathrm{nM} \mathrm{L}-\left[{ }^{3} \mathrm{H}\right]$ glutamate $(50 \mathrm{Ci} / \mathrm{mmol}$. ICN, Irvine, CA). Incubations at higher temperatures $\left(20,30\right.$, and $\left.37^{\circ} \mathrm{C}\right)$ resulted in lower levels of binding. Half of the sections obtained (approximately 34 slides/animal, 12 animals) were also incubated in the presence of $100 \mu \mathrm{M}$ NMDA. With this concentration of NMDA there is no significant displacement of binding to other binding sites known to interact with L-glutamate-KA-, QA- (as labeled by [ ${ }^{3} \mathrm{H}$ ]amino-3-hydroxy-5-methyl-4isoxazolepropionic acid, [ ${ }^{3} \mathrm{H}$ ]AMPA), aspartate-, or L-2-amino-4-phosphonobutyrate-binding sites (Simon et al., 1976; London and Coyle, 1979; Sharif and Roberts, 1981; Honore et al., 1982; Butcher et al., 1983; Fagg et al., 1983; Monaghan et al., 1983a, b, 1984a). However, this concentration is high enough to displace greater than $90 \%$ of the binding to NMDA sites (Monaghan et al., 1983a; ragg and Matus, 1984; Olverman et al., 1984).

Following incubation, unbound radioactivity was removed by dipping the slides into a series of four Coplin jars with ice-cold buffer for a total time of $30 \mathrm{sec}$. Sections were then dried under an air stream and placed into x-ray cassettes with tritium-sensitive film (LKB Instruments, Gaithersburg, MD) and brain paste standards (Unnerstall et al., 1982). Film exposure was 2 to 4 weeks at $4^{\circ} \mathrm{C}$, followed by standard film development in Kodak D- 19 at $20^{\circ} \mathrm{C}$. Autoradiograms were analyzed by computer-assisted densitometry with a De Anza image processing system, LSI-11/23 microprocessor, and a video camera as previously described (Walters and Berns, 1981). The distribution of NMDA-specific $\mathrm{L}-\left[{ }^{3} \mathrm{H}\right]$ glutamate binding (Table I) was determined by subtracting the levels of binding found in various brain regions in the presence of $100 \mu \mathrm{M}$ unlabeled NMDA from the levels of total glutamate binding in the respective regions. This analysis was necessary because, although relatively minor in number, the NMDA-insensitive glutamate-binding sites exhibit a differing distribution. It should be noted that because of the differential quenching of tritium beta emissions by white matter and gray matter (Alexander et al., 1981), the resulting quantitative values presented here are partially a function of this effect. These values, however, are comparable to the quantitative values generated by others for other receptors and may be corrected as correction values become available. Brain regions were identified by comparison of the autoradiograms and Nissl-stained tissue sections to the rat brain atlas by Paxinos and Watson (1982). Cortical regions were compared to regions defined by Krieg (1946).

The radiolabel in the tissue at the end of the binding incubation appeared to be L-glutamate. I - $\left[^{3} \mathrm{H}\right]$ Glutamate hound to tissue sections and then extracted with $0.1 \mathrm{M}$ acetic acid co-migrated with authentic glutamate on cellulose thin layer chromatography plates in an aqueous phenol solvent system.

In tissue sections used for kinetic and equilibrium binding measurements in whole tissue sections, the sections were treated as described above, but instead of fully air-drying the tissue, the sections were wiped ufl the slide with Whatman GF/B glass fiber filters. The radioactivity in these sections was then determined by routine liquid scintillation spectrophotometry. Chemicals were obtanned trom Sigma Chemical Co. (St. Louis, MO) except unlabeled NMDA, which was obtained from Tocris Chemicals (Essex, United Kingdom).

\section{Results}

\section{Binding characteristics}

$\mathrm{L}-\left[{ }^{3} \mathrm{H}\right]$ Glutamate bound to rat brain tissue sections in a saturable, reversible manner with a $K_{d}$ of $0.48 \pm 0.07 \mu \mathrm{M}$ and a $B_{\max }$ of $0.95 \pm$ $0.09 \mathrm{pmol} / \mathrm{mg}$ of protein (Fig. 1). Binding affinity determined within the stratum radiatum of the hippocampus using quantitative densitometry revealed an affinity of $0.24 \pm 0.06 \mu \mathrm{M}$ and a $B_{\max }$ of $3.31 \pm$ $0.41 \mathrm{pmol} / \mathrm{mg}$ of protein, reflecting the higher levels of binding in this region. Equilibrium levels of binding were rapidly achieved (Fig. $1 A)$. The association rate constant was $0.32 \pm 0.02 \mu \mathrm{M}^{-1} \mathrm{~min}^{-1}$. Upon dilution, the binding dissociated with a rate of $0.0054 \pm 0.0004$ $\mathrm{sec}^{-1}$ (Fig. $1 \mathrm{~A}$ ). This indicates that approximately $85 \%$ of equilibrium binding levels remain by the end of the $30-\mathrm{sec}$ rinse. Determination of the $K_{d}$ value from association and dissocialion rale constarts results in a $K_{d}$ of $1.0 \mu \mathrm{M}$. This value is in reasonable agreement with
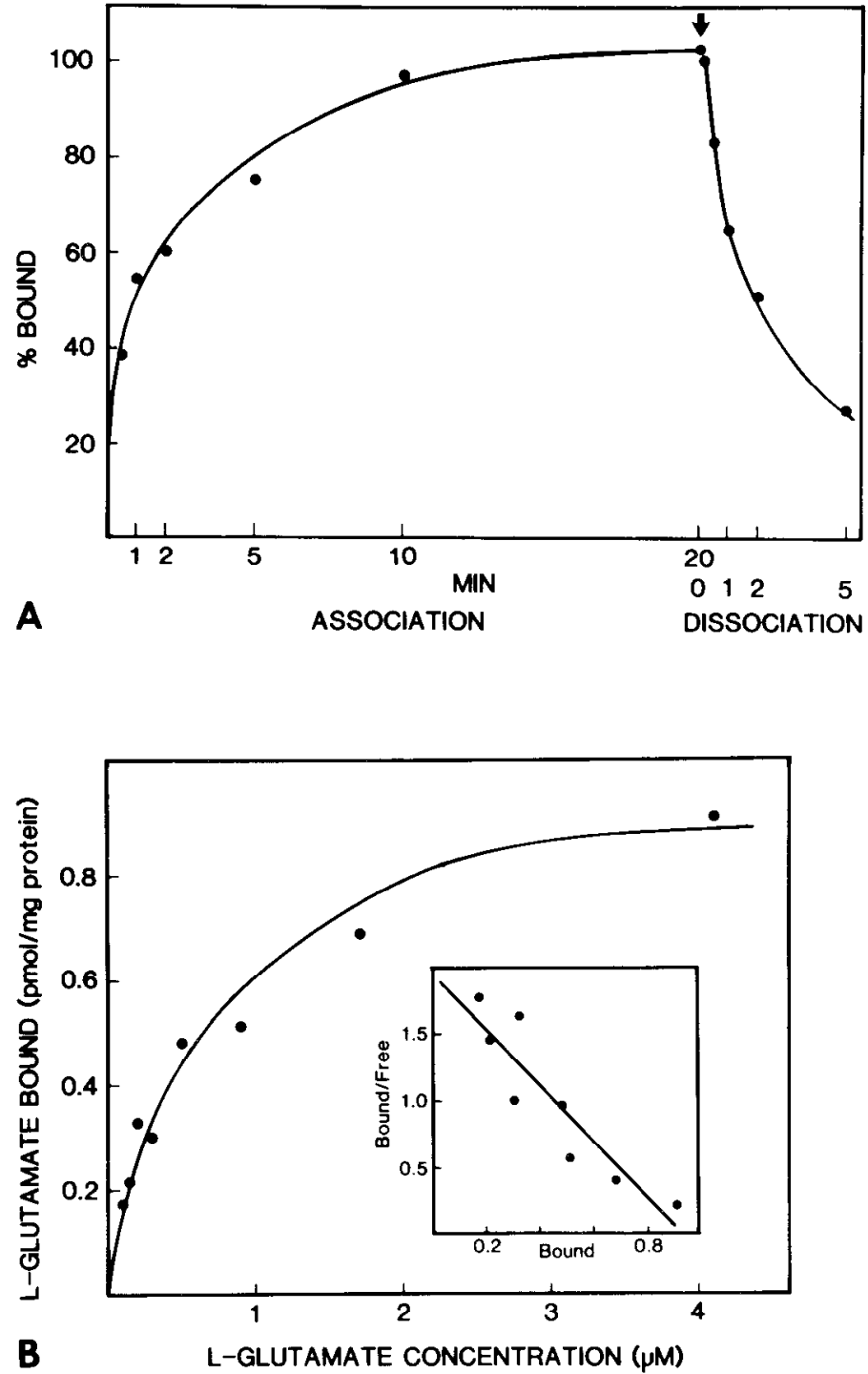

Figure 1. $1 \mathrm{~L}^{3} \mathrm{H}$ Gilutamate $(100 \mathrm{~nm})$ binding to rat brain tissue sections prepared in the coronal plane at a level approximately $3 \mathrm{~mm}$ posterior to bregma. In $A, \%$ Bound is the percentage of specific binding (displaceable by $0.5 \mathrm{~mm}$ L-glutamate). Binding shows rapid association and is readily reversible. Zero rinse time, $100 \%$ binding levels for the dissociation rate experiment were determined by extrapolation. Dissnciation was effected by placing the slide into buffer (at arrow) without the radioligand after the standard incubation as described under "Materials and Methods." In $B$, the dissociation constant was determined by increasing concentrations of unla beled $\mathrm{L}$-glutamate. The inset shows Scatchard analysis of equilibrium binding data (Scatchard, 1949). Representative experiments are shown, and averaged results are presented under "Results."

that determined by equilibrium studies. When binding levels were determined at $7 \mathrm{sec}$ rinse time, higher than expected levels of binding were observed; this may partly be due to the lag time in changing the butter composition surrounding the receptor within the tissue section, or to the presence of a rapidly dissociating component which could not be resolved. However, autoradiograms prepared with a short rinse time $(5 \mathrm{sec})$ exhibited a qualitatively similar distribution pattern, and the $B_{\max }$ value obtained in membrane preparations under conditions with no net dissociation (Yao et al., 1984) is similar to that obtained in this study.

In $50 \mathrm{~mm}$ Tris-acetate buffer and in the absence of $\mathrm{Na}^{+}, \mathrm{Ca}^{2+}$, and $\mathrm{Cl}^{-}$ions, approximately $75 \%$ of the specifically bound $\mathrm{L}-\left[{ }^{3} \mathrm{H}\right]$ glutamate binding was displaced by NMDA with an inhibition constant $\left(K_{\mathrm{i}}\right)$ of $5.2 \pm 1.7 \mu \mathrm{M}(n=3$, Fig. 2$)$. Inhibition constant was determined from the relationship $K_{\mathrm{i}}^{\prime}=\left(1+F / K_{\mathrm{d}}\right)$ where $K_{\mathrm{i}}^{\prime}=$ 


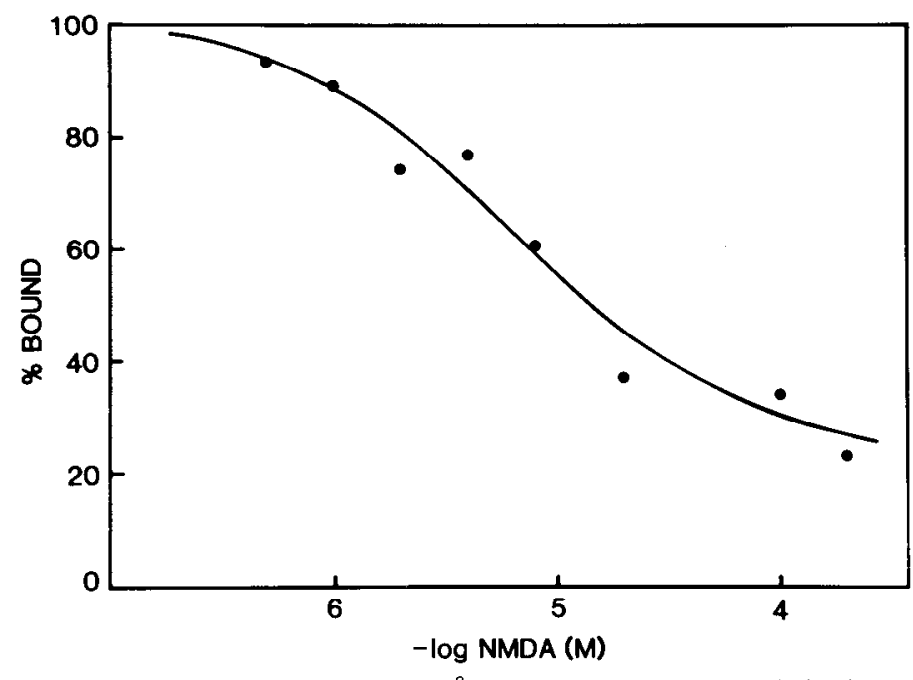

Figure 2. NMDA inhibition of $L-\left[{ }^{3} \mathrm{H}\right]$ glutamate binding to whole tissue sections. Increasing concentrations of NMDA caused an inhibition of binding with a high affinity. Average values are presented under "Results."

- slope $^{-1}$ from the plot of percentage inhibition versus percentage inhibition/concentration of inhibitor, and $F$ and $K_{d}$ represent, respectively, the free concentration and the dissociation constant of $L-\left[{ }^{3} \mathrm{H}\right]$ glutamate. It is unlikely that the binding represents uptake because: (1) $\mathrm{Na}^{+}$and $\mathrm{Cl}^{-}$ions were absent from the incubation buffer (these ions have been reported to be necessary for $\mathrm{Na}^{+}$-dependent uptake (Bennett et al., 1972) and $\mathrm{Cl}^{-}$-dependent uptake (Waniewski and Martin, 1983, 1984)); (2) binding was not decreased by incubating at $0^{\circ} \mathrm{C} ;(3)$ binding is enriched in membrane-solubilized synaptic junctions (Yao et al., 1984) and postsynaptic densities (Fagg and Matus, 1984); and (4) the pharmacological profile does not correspond to glutamate uptake systems (Balcar and Johnston, 1972 Waniewski and Martin, 1984). As previously discussed, the binding site pharmacology corresponds to that expected for the NMDA receptor (Monaghan et al., 1983a) and also corresponds to that determined by using D-[ $\left.{ }^{3} \mathrm{H}\right] \mathrm{AP} 5$ to label NMDA receptors (Olverman et al., 1984).

Distribution of NMDA-sensitive binding sites. The values listed in Table I represent levels of binding which are displaced by $100 \mu \mathrm{M}$ NMDA determined in various brain regions by quantitative autoradiography. As shown in Figure 3, with the conditions used in these experiments, essentially all regions of the brain show a predominately NMDA-sensitive binding site. The most notable exception is the stratum lucidum of the hippocampus (Fig. 3B), where the mossy fiber terminal zone is located. This layer contains a predominately KA-sensitive population of $\mathrm{L}-\left[{ }^{3} \mathrm{H}\right]$ glutamate-binding sites (Monaghan et al, 1983a). NMDA-insensitive binding under the conditions used in this study represent primarily KA-sensitive binding sites and the remainder of the detectable sites are AMPA-sensitive binding sites.

The values shown in table I, along with the autoradiograms shown in Figures 3 to 7, indicate extensive regional variation in the distribution of NMDA sites in rat brain. The general distribution of NMDAsensitive sites is readily seen with a color-enhanced autoradiogram (Fig. 4). Telencephalic structures have high levels of binding. Cerebral cortex, hippocampus, and striatum account for much of the NMDA site binding, whereas midbrain and brainstem have low levels. Overall, binding is higher in dendritic zones than in white matter regions. After taking into account the lower tritium efficiency over white matter (Alexander et al., 1981), there is still a marked preference for dendritic zones. Cell body layers generally have low levels of binding, with the exception of the granule cell layer of the cerebellum

Cerebral cortex exhibits both regional and laminar variations in NMDA site density. These variations are demonstrated in Figure 4. In neocortex the outer layers I to III have a greater density than the deeper layers. In addition, a slightly higher density band was com- monly observed in layer $\mathrm{Va}$ of the cortex. This was most readily observed in parietal cortex (Figs. 4 to 6). Insular, entorhinal, and perirhinal cortices exhibit a uniform density through their layers. Among cortical regions, frontal, insular, pyriform, perirhinal, and anterior cingulate cortex display the highest levels, whereas temporal, occipital and parietal regions display intermediate levels (with slightly lower levels in the deep parietal cortex), and the posterior cingulate cortex displays the lowest levels (cf. Figs. 5 and 6). In parasagittal sections near the midline, a distinct border was observed between anterior and posterior cingulate cortex. Likewise, an abrupt change in receptor density is observed in horizontal sections at the perirhinal-entorhinal border (Fig. 4).

NMDA-sensitive L- $\left[{ }^{3} \mathrm{H}\right]$ glutamate-binding sites are particularly enriched in regions relating to olfaction. Within the olfactory bulb itself, there is a distincl lamination with higher binding levels in the external plexiform layer (Fig. 5A). In addition to high levels in primary olfactory cortex (Fig. 5), the anterior olfactory nuclei as well as the accessory olfactory bulb have high levels of binding (Fig. 5, $B$ and $C$ ). More posteriorly, high levels of binding are associated with the olfactory tubercles (Fig. 5, $C$ to $E$ ).

Within the basal ganglia and basal forebrain, the caudate/putamen and especially the nucleus accumbens exhibit high levels of binding (Fig. 5, $D$ and $E$ ). The globus pallidus, ventral palladium, and substantia innominata have a low density of binding sites with slightly higher levels in the latter two regions (Fig. 5E, Table 1). The bod nucleus of the stria terminalis and medial septum have moderate to low densities, whereas the lateral septum has higher levels of binding (Fig. 5, D and E). The nucleus of the lateral olfactory tract has moderately high levels (Fig. 6A). In the amygdala, the amygdalahippocampal transition region and postcrior cortical amygdala havc high levels of binding, as do the lateral and especially the basolateral amygdaloid nuclei. In contrast, the anterior cortical, central, and medial amygdala regions have relatively low concentrations (Fig. 6 , $A$ and $B$ ).

As previously reported (Monaghan et al., 1983a), the hippocampal formation has a distinctive distribution of NMDA sites. Highest levels are found in the stratum oriens and stratum radiatum of area CA1, and in the inner molecular layer of the dentate gyrus. Moderately high levels are found in CA3 stratum oriens and stratum radiatum, CA1 stratum lacunosum-moleculare, and the dentate gyrus outer (outer two-thirds) molecular layer. Low levels are found over the cell body layers, the hilar region, and the stratum lucidum of CA3 (Fig. $6, B$ and $C$ )

In general, the thalamus has moderate levels of binding whereas the hypothalamus has low levels. Within the thalamus the anterior dorsal, lateral dorsal, lateral posterior, and midline nuclei (i.e., rhomboid, reuniens, mediodorsal, intermediodorsal, and central medial thalamic nuclei) have slightly higher levels than the ventroposterior and ventrolateral nuclei. The thalamic reticular nucleus and zona incerta have approximately half the binding of the former thalamic regions (Fig. 6, $A$ and $B$; Table 1). Geniculate regions also have moderate levels with the dorsal medial geniculate showing higher levels than the ventral medial geniculate. Dorsal lateral geniculate nucleus has intermediate amounts. Hypothalamic regions are low in binding, as is the habenula.

Midbrain regions exhibit low levels of binding with the exception of higher levels in the central gray (especially the dorsal portion), the superficial gray layer of the superior colliculus, the interpeduncular nucleus, and the cuneiform nucleus. The inferior colliculus exhibits a gradient in NMDA site density with higher levels in the dorsal medial region and lower levels in the ventral lateral region (Fig. 7, B and $C$ ). This gradient roughly parallels that seen for glutamate levels (Adams and Wenthold, 1979). As shown in Figure 7, the brain stem shows little binding, but higher levels were found in the parabrachial nucleus, the nucleus of the solitary tract, the inferior olivary complex, the hypoglossal nucleus, the medial vestibular nucleus and the granule cell layer of the dorsal cochlear nucleus. Within the parabrachial nucleus, a small region in the lateral portion, which corresponds to the Kolliker-Fuse nucleus (Paxinos and Watson, 1982), shows 
TABLE I

Distrbution of NMDA-sensitive $L-\left[{ }^{3} \mathrm{H}\right]$ glutamate-binding siles

These values represent the amount of $L-\left[{ }^{3} \mathrm{H}\right]$ glutamate binding $(100 \mathrm{nM})$ inhibited by the presence of $100 \mu \mathrm{M}$ NMDA. Values are the averages obtained from three to eight animals \pm SEM.

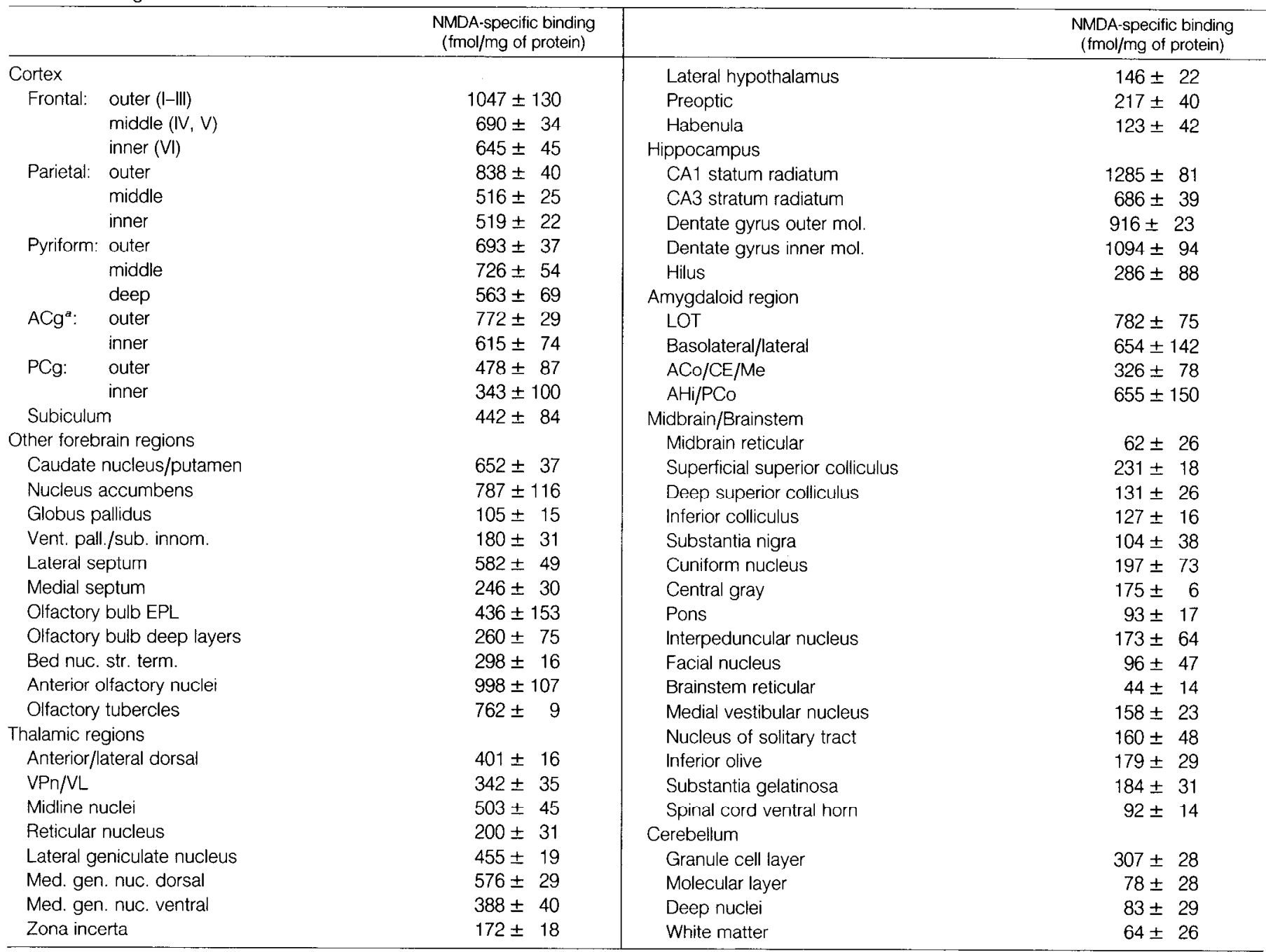

${ }^{2} \mathrm{ACg}$, anterior cingulate cortex; $\mathrm{ACO}$, anterior cortical amygdaloid nucleus; $\mathrm{AHi}$, amygdalohippocampal area; Bed nuc. str. term., bed nucleus of the stria terminalis; $\mathrm{CE}$, ccntral amygadaloid nucleus; EPL, external plexiform layer; LOT, nucleus of the lateral olfactory tract; Me, medial amygdaloid nucleus; Med. gen. nuc., medial geniculate nucleus; mol., molecular layer; PCg, posterior cingulate nucleus; PCo, posterior cortical amygdaloid nucleus; sub. innom., substantia innominata; Vent. pall., ventral pallidum; VL, ventral lateral nucleus of thalamus; VPn, ventral posterior nucleus of thalamus.

clearly higher levels of binding (Fig. 7C). The cerebellum has higher levels of binding in the granule cell layer than in the molecular layer and deep nuclei (Fig. 7, $D$ to $F$ ). The spinal cord is low in these binding sites with the exception of the substantia gelatinosa of the dorsal horn (Fig. $7 F$ ). It is notable that the red nucleus, the pons, and the mamillary bodies exhibit low binding similar to the midbrain and brainstem reticular regions.

\section{Discussion}

NMDA recognition sites are distributed throughout the CNS with a marked anatomical specificity. In agreement with studies using $\mathrm{D}$ $\left[{ }^{3} \mathrm{H}\right] \mathrm{AP} 5$ to label NMDA receptors (Monaghan et al., 1984b; Olverman et al., 1984), highest levels are found in the hippocampus. Other high density regions include the outer layer of cerebral cortex, nucleus accumbens, striatum, anterior olfactory nuclei, and various thalamic, brainstem, and amygdaloid nuclei. Exceptionally low binding levels are found in the presumably GABAergic globis pallidus and habenula, as well as in the reticular formation and other hindbrain regions.
Others have recently described the autoradiographic pattern following the incubation of rat brain tissue sections with radiolabeled glutamate (Greenamyre et al., 1983; Halpain et al., 1984). The conditions used by these authors, most notably the presence of $\mathrm{Cl}^{-}$ ions in the incubation buffer, result in an increase in apparent binding which does not have the same pharmacological or anatomical characteristics as the NMDA-sensitive sites (Monaghan et al., 1983a). This explains why neither of the other papers reported significant displacement by NMDA.

The distribution of binding largely corresponds to that of other markers for glutamate-using pathways (for reviews, see Cotman and Nadler, 1981; Watkins and Evans, 1981; Fagg and Foster, 1983; Fonnum, 1984). D- $\left[{ }^{3} \mathrm{H}\right]$ Aspartate or L- $\left[{ }^{3} \mathrm{H}\right]$ glutamate uptake shows high levels in the hippocampus, striatum, nucleus accumbens, lateral septum, and cerebral cortex (especially the outer layers). In general, these systems have been shown to exhibit a decrease in either endogenous glutamate levels or evoked release of glutamate tollowing lesions which eliminate the presynaptic terminals. Furthermore, there is electrophysiological/pharmacological evidence for glutamate being a transmitter in many of these regions-e.g., striatum, hippo- 

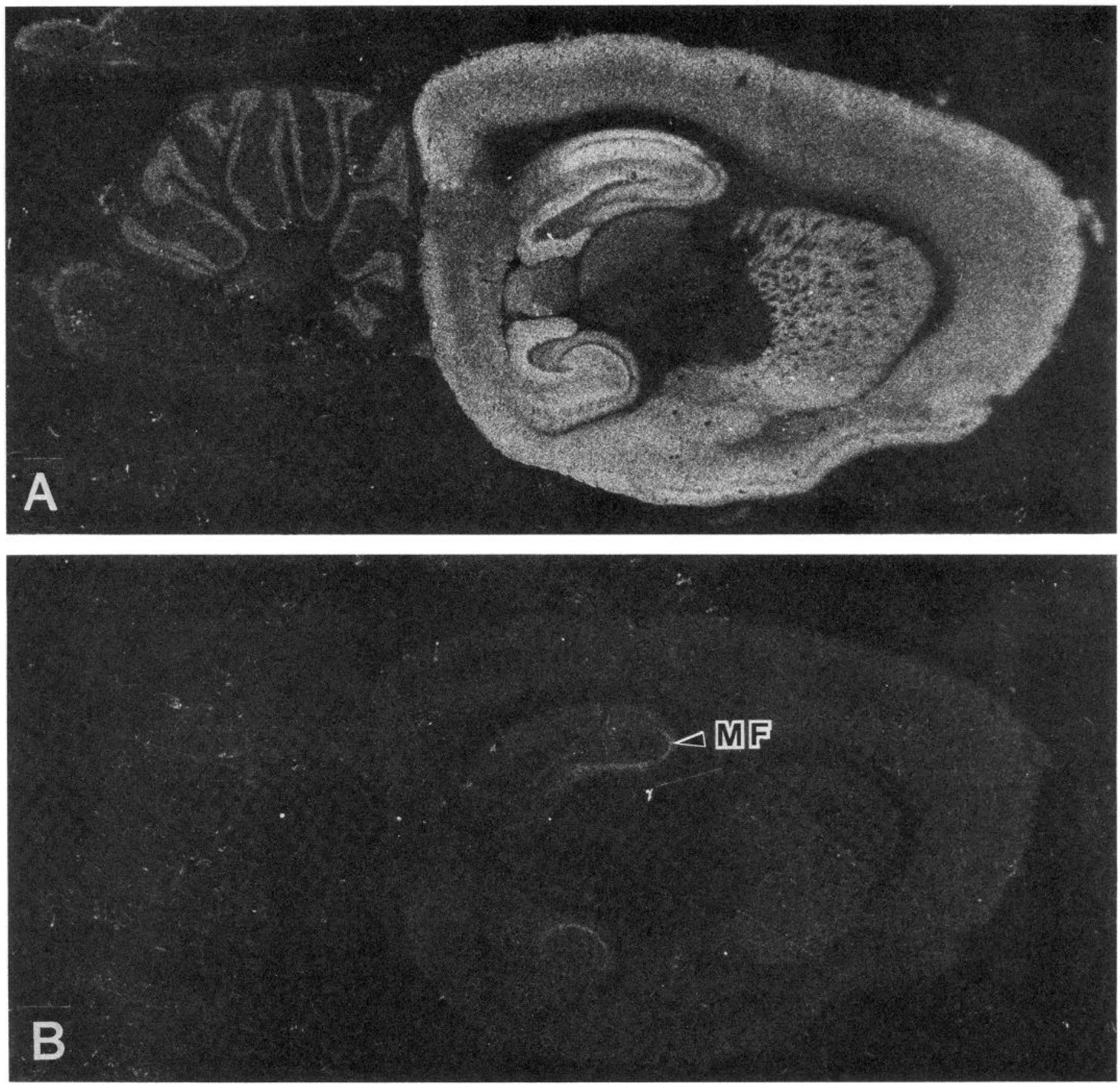

Figure 3. Tritium-sensitive film autoradiograms of L- $\left[{ }^{3} \mathrm{H}\right]$ glutamate binding printed directly; regions of high binding site density appear bright. $A$ and $B$ are sagittal sections of rat brain mounted on microscope slides and incubated with $\left.100 \mathrm{nM} \mathrm{L} \cdot{ }^{3} \mathrm{H}\right]$ glutamate as described in the text. In $B$, radioligand was incubated in the presence of $100 \mu \mathrm{M}$ NMDA, which inhibited the binding in nearly all brain regions with the major exception of the hippocampal stratum lucidum, termination zone of the mossy fiber system (MF).

campus, cortex, solitary tract nucleus, and dorsal horn of spinal cord. Other recent reports have provided further correspondence between glutamate-using pathways and regions with a high density of NMDA sites, for example, the nucleus of the lateral olfactory tract (Fuller et al., 1984) and the dorsal cochlear nucleus (Potashner, 1983).

Most regions proposed to use NMDA receptors in synaptic transmission exhibit relatively high levels of NMDA site binding. On the basis of pharmacological characterization, it has been proposed that the stratum radiatum of hippocampus (Collingridge et al., 1983; Harris et al., 1984; Wigstrom and Gustafsson, 1984; Hablitz and Langmoen, 1984; Coan and Collingridge, 1985), intracortical path- ways (Hicks and Geddes, 1981), and olfactory cortex (Collins, 1982) use NMDA receptors for synaptic transmission. These regions contain significant levels of binding sites for NMDA. Using ion-sensitive electrodes, Pumain and Heinemann (1981) and Pumain et al. (1984) found that L-glutamate and NMDA excitation in the rat cerebral cortex exhibited a laminar distribution parallel to the distribution of NMDA sites within the cortex; greater L-glutamate and NMDA response was found in the superficial cortical layers. Luini et al. (1981) reported that NMDA was the most potent agonist tested in eliciting $\mathrm{Na}^{+}$fluxes in striatal slices. Also consistent with the NMDA receptor distribution described here are the observations of Perkins and Stone (1983) who found that the NMDA agonist quinolinate and 


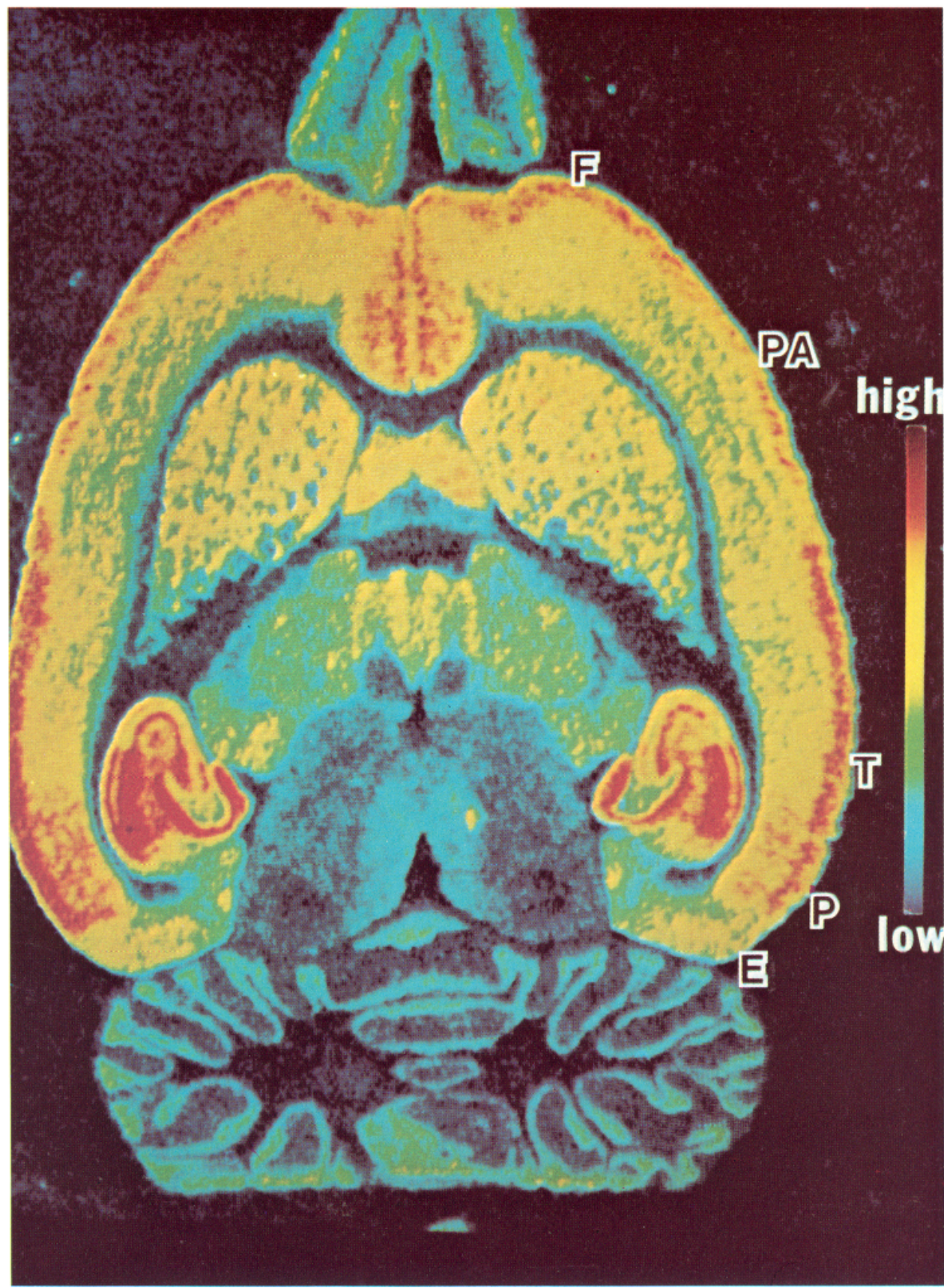

Figure 4. Computer-generated, color-enhanced L- $\left[{ }^{3} \mathrm{H}\right]$ glutamate-binding site autoradiogram. The color generation program (Altar et al., 1984) represents binding site density by color with high to low values indicated by: red-yellow-green-blue. The autoradiogram was prepared as previously described (Monaghan et al., 1983a). With color enhancement, variations within the cerebral cortex become readily apparent; note the relatively low levels of binding in the parietal cortex and the lack of lamination within the entorhinal cortex. $E$, entorhinal cortex; $F$, frontal cortex; $P$, perirhinal cortex; $P A$, parietal cortex; $T$, temporal cortex.

NMDA exhibit higher potencies in cortex, hippocampus, and striatum than in lower brain structures. It is difficult to compare the autoradiographically determined distribution of NMDA sites to various other studies of the blockade of synaptic responses by iontophoretically applied NMDA antagonists because the antagonist concentration and, hence, the specificity are uncertain. Furthermore, extracellularly recorded EPSP response inhibition by NMDA antagonists may not reveal NMDA receptor activity (Collingridge et al., 1983; Hablitz and Langmoen, 1984; Harris et al., 1984; Wigstrom and Gustafsson, 1984; Coan and Collingridge, 1985). Thus, the distribution of NMDA sites described here is consistent with that expected for NMDA sites.
Given the tentative correspondence between NMDA-binding sites and regions which use NMDA receptors, one would predict that the regions described above which have a high density of NMDA sites are likely to use this receptor in excitatory amino acid neurotransmission. Although it is often difficult to associate a specific pathway with a region of high NMDA site density, it is worth noting that some regions which exhibit variations in NMDA site density also exhibit similar variations in their cortical afferents. For example, regions of high binding site density within the amygdala and the cingulate cortex receive cortical inputs different from those in the respective low density regions (Vogt et al., 1981; Ottersen, 1982).

Some regions thought to use an excitatory amino acid as a 

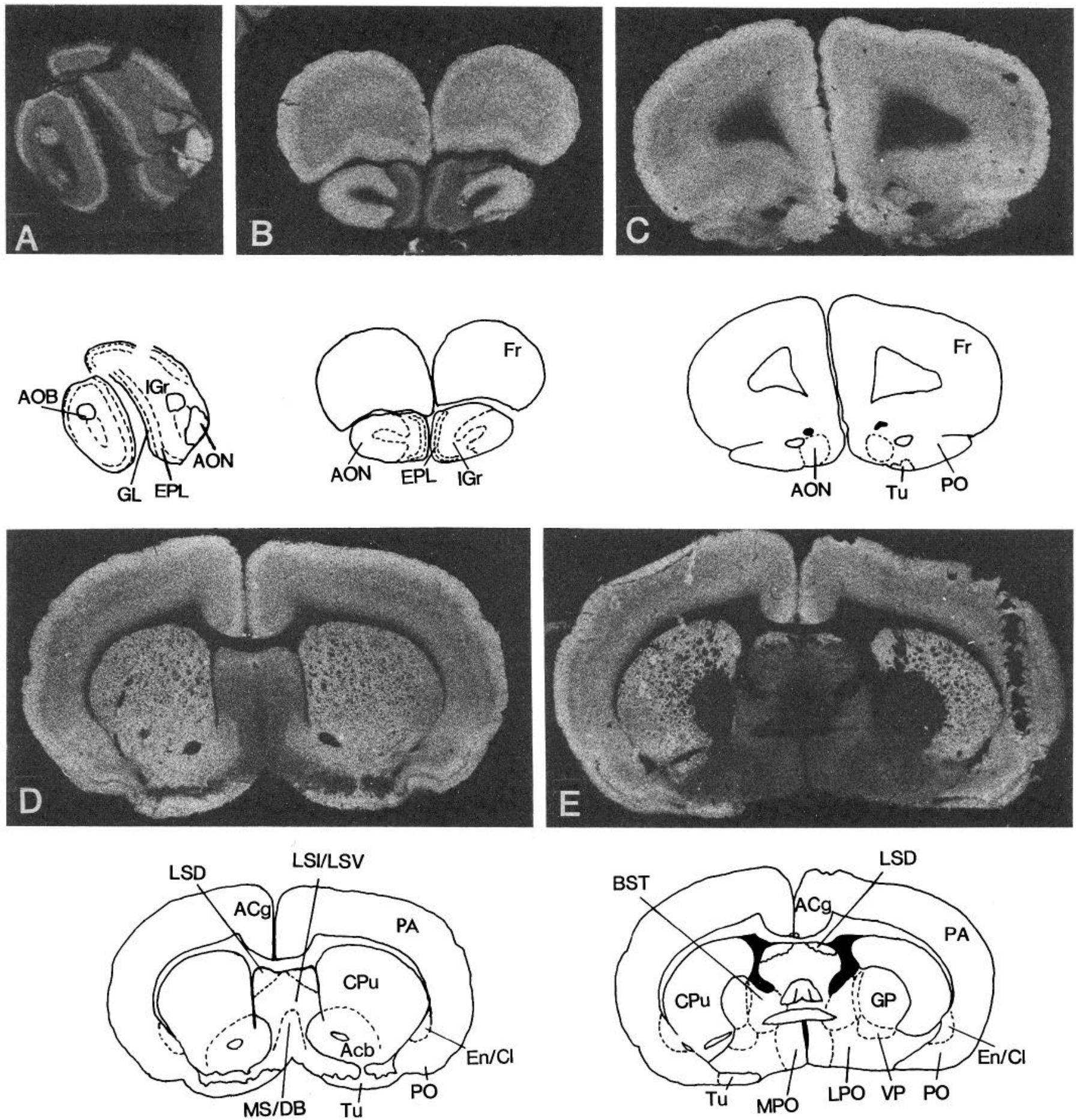

Figures 5 to 7. Coronal sections of rat brain L.-[3H]glutamate autoradiograms prepared as described under "Materials and Methods." The distribution of total glutamate binding (shown) is qualtitatively the same as the NMDA-specific distribution with the exception of the lower density of NMDA-specific sites found in the stratum lucidum. $A c b$, nucleus accumbens; $A C g$, anterior cingulate cortex; $A O B$, accessory olfactory bulb; $A O N$, anterior olfactory nuclei; $B S T$, bed nucleus of stria terminalis; $\mathrm{Cl}$, claustrum; $C P u$, caudate putamen; $D B$, diagonal band nucleus; $E n$, endopiriform nucleus; $E P L$, external plexiform layer; $F r$, frontal cortex; GL, glomerular layer of olfactory bulb; GP, globus pallidus; IGr, internal granular layer; $L P O$, lateral preoptic area; $L S D$, lateral septum, dorsal; $L S I$, lateral septum, intermediate; $L S V$, lateral septum, ventral; $M P O$, medial preoptic area; $M S$, medial septal nucleus; $P A$, parietal cortex; $P O$, primary olfactory cortex, pyriform cortex; $T u$, olfactory tubercle; VP, ventral pallidum

transmitter do not have a high density of NMDA-sensitive sites. The corticofugal targets, red nucleus and pons, do not have relatively high levels of binding; neither do the trigeminal nucleus, the mamillary bodies, the substantia nigra, or the molecular layer of cerebellum. It is possible that there is a trend for motor-associated, ventrally located, glutamate-using pathways to have a lower density of NMDA sites than the cortical, limbic, and sensory-associated glutamateusing pathways. If NMDA receptors have a primarily modulatory function, then their differential localization may reflect regions with differing modulatory regulation.

Recent reports have provided interesting evidence regarding the function of NMDA receptors in the CNS. Patch-clamp and voltage- 

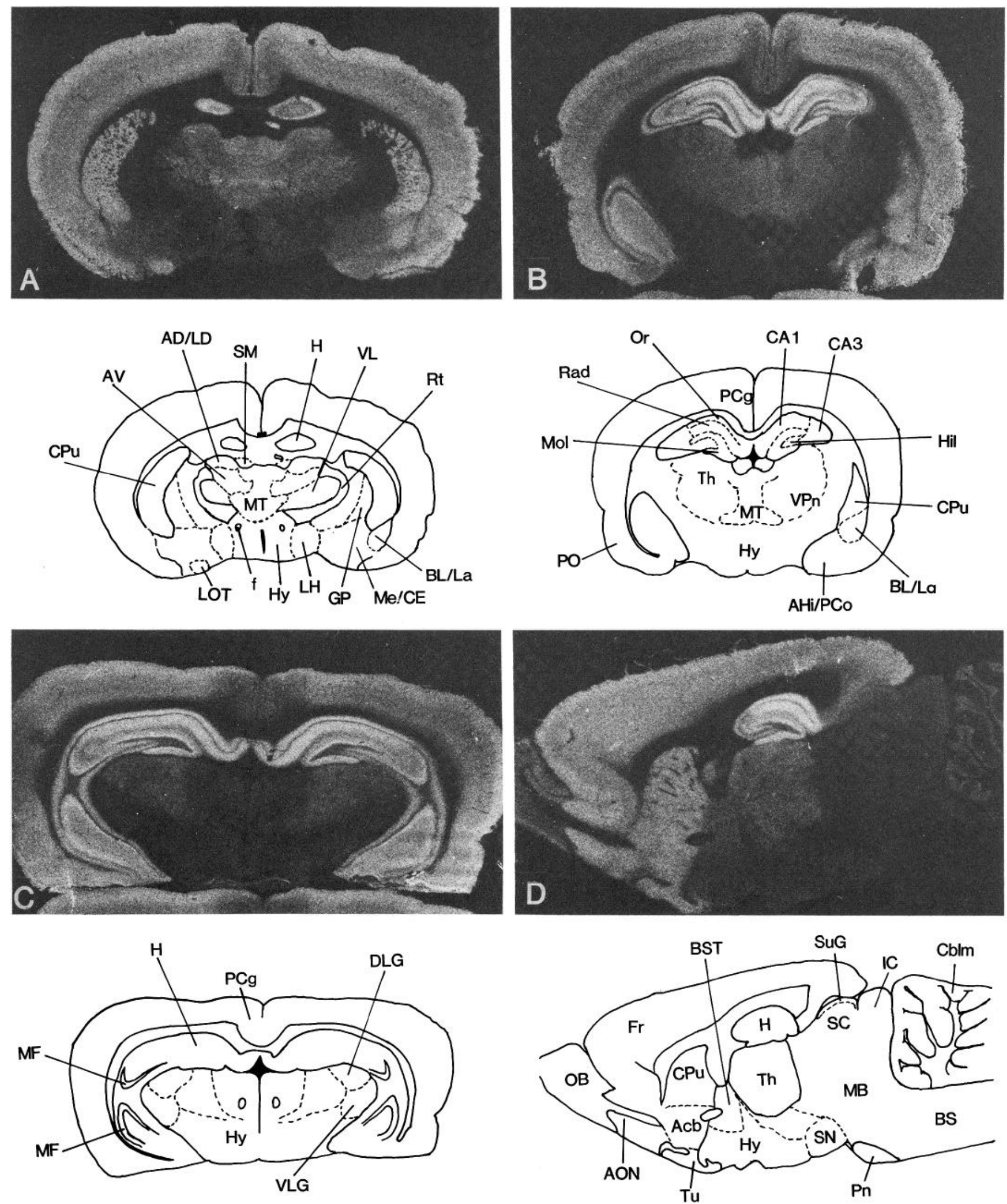

Figure 6. Abbreviations: $A c b$, nucleus accumbens; $A D$, anterior dorsal thalamic nucleus; $A H i$, amygdalohippocampal area; $A O N$, anterior olfactory nuclei; $A V$, anterior ventral nucleus of thalamus; $B L$, basolateral amygdaloid nucleus; $B S$, brainstem; $B S T$, bed nucleus of stria terminalis; $C b / m$, cerebellum; $C E$, central amygdaloid nucleus; $C P u$, caudate putamem; $D L G$, dorsal lateral geniculate; $f$, formix; $F r$, frontal cortex; GP, globus pallidus; $H$, hippocampus; $H i l$, hilus; $H y$, hypothalamus; IC, inferior colliculus; $L a$, lateral amygdaloid nucleus; $L D$, lateral dorsal thalamic nucleus; $L H$, lateral hypothalamus; $L O T$, nucleus of lateral olfactory tract; $M B$, midbrain; $M e$, medial amygdaloid nucleus; $M F$, mossy fiber termination zone; $M o l$, mol, dentate gyrus, molecular layer; MT, midline thalamic nuclei; $O B$, olfactory bulb; $O r$, stratum oriens; $P C g$, posterior cingulate cortex; $P C o$, posterior cortical amygdaloid nucleus; $P n$, pons; $R a d$, stratum radiatum; $R$ t, reticular thalamic nucleus; $S C$, superior colliculus; $S M$, stria medullaris; $S N$, substantia nigra; SuG, superficial gray layer of the superior colliculus; $T h$, thalamus; $T u$, olfactory tubercle; $V L$, ventral lateral nucleus of thalamus; VLG, ventral lateral geniculate; VPn, ventral posterior nucleus of thalamus. 

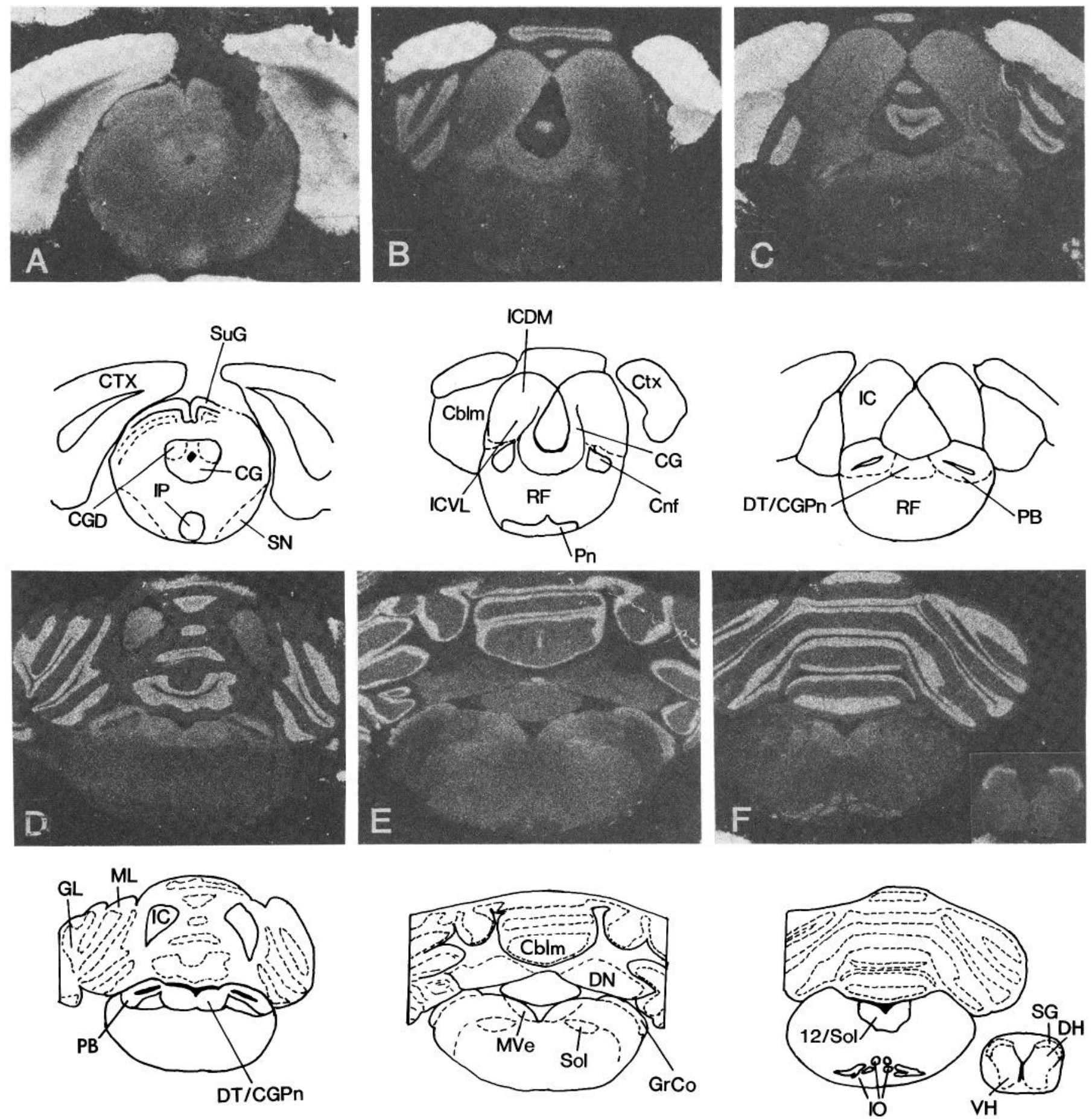

Figure 7. Abbreviations: 12 , hypoglossal nucleus; $C b / m$, cerebellum; CG, central gray; CGD, central gray, dorsal; CGPn, central gray pons; Cnf, cuneiform nucleus; $C T X, C t x$, cerebral cortex; $D H$, dorsal horn; $D N$, deep nuclei of the cerebellum; $D T$, dorsal tegmental nucleus; $G L$, granule cell layer of cerebellum; GrCo, granule cell layer of cochlear nucleus; IC, inferior colliculus; ICDM, inferior colliculus, dorsomedial; ICVL, inferior colliculus, ventrolateral; $I O$, inferior olive; $I P$, interpeduncular nucleus; $M L$, molecular layer of cerebellum; $M V e$, medial vestibular nucleus; $P B$, parabrachial nucleus; $P n$, pons; $R F$, reticular formation; SG, substantia gelatinosa; SN, substantia nigra; Sol, nucleus of the solitary tract; SuG, superficial gray layer of the superior colliculus; VH, ventral horn of spinal cord.

clamp experiments indicate that NMDA receptors activate a channel which exhibits voltage-dependent behavior in the presence of $\mathrm{Mg}^{2+}$ (Flatman et al., 1983; Mayer et al., 1984; Nowak et al., 1984). Within the region of highest binding site density, the stratum radiatum of CA1 hippocampus, NMDA receptor blockade blocks the formation of long-term potentiation without blocking the extracellularly recorded EPSP. Together these results indicate that NMDA receptor function may be more complex than the generation of fast EPSPS.
A modulatory function could also explain why NMDA-binding sites exhibit a largely overlapping distribution with the other excitatory amino acid receptors, QA, as labeled by $\left.{ }^{3} \mathrm{H}\right] \mathrm{AMPA}$ (Monaghan et al., 1984a; Rainbow et al., 1984), and KA, as labeled by $\left[{ }^{3} \mathrm{H}\right] \mathrm{KA}$ (Monaghan and Cotman, 1982; Unnerstall and Wamsley, 1983). Thus, one region may have two receptors for the same transmitter. In CA1 hippocampus, most evidence favors a KA/QA receptor for mediation of the Schaffer collateral EPSP (Koerner and Cotman, 
1982; Collingridge et al., 1983; Ganong et al., 1984). This is consistent with the high density of $\left[{ }^{3} \mathrm{H}\right] \mathrm{AMPA}$-binding sites found within this region. In addition, we find a high density of NMDA sites within this region, and recent evidence strongly indicates that these sites are also physiologically relevant to neurotransmission at this synapse. With evidence for the presence of both L-glutamate and Laspartate at this pathway (Cotman and Nadler, 1981), it is possible that these are both released and L-aspartate interacts predominately with the NMDA site, whereas glutamate interacts with both.

In addition to the significance of the transmitter function of the NMDA receptor, Meldrum and colleagues (Croucher et al., 1982; Meldrum et al., 1983a, b) have shown that NMDA receptors are of clinical importance. Seizures induced by various agents are blocked by NMDA antagonists. Furthermore, ischemia-induced cell damage in the hippocampus is also blocked by NMDA antagonists (Simon et al., 1984). With the findings of this report, that the receptors for NMDA show a selective localization to cortical and hippocampal regions and a relative low density in hypothalamic, midbrain, and brainstem regions, it seems possible that NMDA antagonists may have therapeulic potential in that they may be selective for higher brain excitatory circuits and not interfere with lower brain vegetative functions.

\section{References}

Adams, J. C., and R. J. Wenthold (19/9) Distribution of putative amino acid transmitters, choline acetyltransferase and glutamate decarboxylase in the inferior colliculus. Neuroscience 4: 1947-1951.

Alexander, G. M., R. J. Schwartzman, R. D. Bell, J. Yu, and A. Renthal (1981) Quantitative measurement of local cerebral metabolic rate for glucose utilizing tritiated 2-deoxyglucose. Brain Res. 223: 59-67.

Altar, A. C., R. J. Walter, K. A. Neve, and J. F. Marshall (1984) Computerassisted video analysis of $\left[{ }^{3} \mathrm{H}\right]$-spiroperidol binding autoradiographs. $\mathrm{J}$ Neurosci. Methods 10: 173-188.

Balcar, V. J., and G. A. R. Johnston (1972) The structural specificity of the high affinity uptake of L-glutamate and L-aspartate by rat brain slices. J. Neurochem. 19: 2657-2666

Bennett, J. P. W. J. Logan, and S. H. Snyder (1972) Amino acid neurotransmitter candidates: Sodium dependent high-affinity uptake by unique synaptosomal tractions. Science 178: 997-999.

Butcher, S. P., J. F. Collins, and P. J. Roberts (1983) Characterization of the binding of $\mathrm{DL}-\left[{ }^{3} \mathrm{H}\right]-2$-amino-4-phosphonobutyrate to L-glutamate-sensitive sites on rat brain synaptic membranes. Br. J. Pharmacol. 80: 355-364.

Coan E. J., and G. L. Collingridge (1985) Magnesium ions block an $N$-methyl$\mathrm{D}$-aspartate receptor-mediated component of synaptic transmission in rat hippocampus. Neurosci. Lett. 53: 21-26.

Collingridge, G. L., S. J. Kehl, and H. McLennan (1983) Excitatory amino acids in synaptic transmission in the Schaffer-commissural pathway of the rat hippocampus. J. Physiol. (Lond.) 334: 33-46.

Collins, G. G. S. (1982) Some effects of excitatory amino acid receptor antagonists on synaptic transmission in the rat olfactory cortex slicc. Brain Res. 244: 311-318.

Cotman, C. W. A C. Foster, and T. Lanthorn (1981) An overview of glutamate as a neurotransmitter. Adv. Biochem. Psychopharmacol. 27: 1-27.

Cotman, C. W., and J. V. Nadler (1981) Glutamate and aspartate as hippocampal transmitters: Biochemical and pharmacological evidence. In Glutamate: Transmitter in the Central Nervous System, P. J. Roberts, J. Storm-Mathisen, and G. A. R. Johnston, eds., pp. 117-154, John Wiley \& Sons LTD, London.

Croucher, M. J., J. F. Collins, and B. S. Meldrum (1982) Anticonvulsant action of excitatory amino acid antagonists. Science 216: 899-901.

Davies, J., and J. C. Watkins (1983) Role of excitatory aminn acid receptors in mono- and polysynaptic excitation in the cat spinal cord. Exp. Brain Res. 49: 280-290

Fagg, G. E., and A. C. Foster (1983) Amino acid neurotransmitters and their pathways in the mammalian central nervous system. Neuroscience 9: 701-719.

Fagg, G. E., A. C. Foster, E. E. Menia, and C. W. Cotman (1983) Chloride and calcium ions separate L-glutamate receptors in synaptic membranes. Eur. J. Pharmacol. 88: 105-110.

Fagg, G. E., and A. Matus (1984) Selective association of N-methyl-aspartate and quisqualate types of $L$-glutamate receptor with brain postsynaptic densities. Proc. Natl. Acad. Sci. U. S. A. 81: 6876-6880.
Flatman, J. A., P. C. Schwindt, W. E. Crill, and C. E. Stafstrom (1983) Multiple actions of $N$-methyl-D-aspartate on cat neocortical neurons in vitro. Brain Res. 266: 169-173.

Fonnum. F. (1984) Glutamate: A neurotransmitter in the mammalian brain. J. Neurochem. 42: 1-11

Foster, A. C., and G. E. Fagg (1984) Acidic amino acid binding sites in mammalian neuronal membranes: Their characteristics and relationship to synaptic receptors. Brain Res. Rev. 7: 103-164

Fuller, T. A., F. T. Russchen, and J. L. Price (1984) Presumptive glutamatergic/aspartergic (GLU/ASP) cells projecting to the olfactory cortex. Soc. Neurosci. Abstr. 10: 227.

Ganong, A. H., C. W. Cotman, A. W. Jones, and J. C. Watkins (1984) Analogues of piperazine-2,3-dicarboxylic acid inhibit excitatory synaptic transmission in rat hippocampal slices. Soc. Neurosci. Abstr. 10: 228.

Greenamyre, J. T., A. B. Young, and J. B. Penny (1983) Quantitative autoradiography of $\mathrm{L}-\left[{ }^{3} \mathrm{H}\right]$-Glutamate-binding to rat brain. Neurosci. Lett 37: 155-160.

Hablitz, J. J., and I. A. Langmoen (1984) Possible NMDA receptor mediation of synaptic transmission in the hippocampal CA1 region. Soc. Neurosci. Abstr. 10: 415

Halpain, S., C. M. Wieczorek, and T. C. Rainbow (1984) Localization of Lglutamate receptors in rat brain by quantitative autoradiography. J. Neurosci. 4: 2247-2258.

Harris, E. W. A. H. Ganong, and C. W. Cotman (1984) Long-term potentiation in the hippocampus involves activation of $\mathrm{N}$-methyl-D-aspartate receptors. Brain Res. 323: 132-137

Hicks, T. P., and R. C. A. Geddes (1981) Synaptic transmission in suprasylvian visual cortex is reduced by excitatory amino acid antagonists. Can. J. Physiol. Pharmacol. 59: 893-896.

Honore, T., J. Lauridsen, and P. Krogsgaard-Larsen (1982) The binding of ${ }^{3} \mathrm{H}$-AMPA, a structural analogue of glutamic acid, to rat brain membranes. J. Neurochem. 38: 173-178.

Koerner, J. F., and C. W. Cotman (1982) Response of Schaffer collateralCA1 pyramidal cell synapses of the hippocampus to analogues of acidic amino acids. Brain Res. 251: 105-115.

Krieg, W. J. S. (1946) Connections of the cerebral cortex. J. Comp. Neurol. 84: 221-275.

London, E. D., and J. T. Coyle (1979) Specific binding of ${ }^{3} \mathrm{H}$-kainic acid to receptor sites in rat brain. Mol. Pharmacol. 15: 492-505.

Luini, A. O., Goldberg, and V. Teichberg (1981) Distinct pharmacological properties of excitatory amino acid receptors in the rat striatum: Study by $\mathrm{Na}^{+}$efflux assay. Proc. Natt. Acad. Sci. U. S. A. 78: 3250-3254.

Mayer, M. L., G. L. Westbrook, and P. B. Guthrie (1984) Voltage-dependent block by $\mathrm{Mg}^{2+}$ of NMDA responses in spinal cord neurones. Nature 309 . 261-263.

McLennan, $H$. (1981) On the nature of the receptors for various excitatory amino acids in the mammalian central nervous system. Adv. Biochem. Psychopharmacol. 27: 253-262.

Meldrum, B. S., M. J. Croucher, G. Badman, and J. F. Collins (1983a) Antiepileptic actions of excitatory amino acid antagonists in the photosensitive baboon, Papio papio. Neurosci. Lett. 39: 101-104.

Meldrum, B. S., B. Wardley-Smit, M. Halsey, and J. -C. Rostein (1983b) 2 Aminophosphonoheptanoic acid protects against the high-pressure neurological syndrome. Eur. J. Pharmacol. 87: 501-502.

Monaghan, D. T., and C. W. Cotman (1982) Distribution of ${ }^{3} \mathrm{H}-\mathrm{kainic}$ acid binding sites in rat CNS as deterrmined by autoradiography. Brain Res 252: $91-100$.

Monaghan, D. T., V. R. Holets, D. W. Toy, and C. W. Cotman (1983a) Anatomical distributions of four pharmacologically distinct ${ }^{3} \mathrm{H}-\mathrm{L}$-glutamate binding sites. Nature 306: 176-179.

Monaghan, D. T., M. C. MCMills, A. R. Chamberlin, and C. W. Cotman (1983b) Synthesis of $\left[{ }^{3} \mathrm{H}\right]-2$-amino-4-phosphonobutyric acid and characterization of its binding to rat brain membranes: A selective ligand for the chloride/calcium-dependent class of L-glutamate binding sites. Brain Res. 278: $137-144$.

Monaghan, D. T., D. Yao, and C. W. Cotman (1984a) Distribution of $\left[{ }^{3} \mathrm{H}\right]$ $A M P \wedge$ binding sites in rat brain as determined by quantitative autoradiog. raphy. Brain Res. 324: 160-164.

Monaghan, D. T., D. Yao, H. J. Olverman, J. C. Watkins, and C. W. Cotman (1984b) Autoradiography of $\mathrm{D}-\left[{ }^{3} \mathrm{H}\right]$-2-amino-5-phosphonopentanoate binding sites in rat brain. Neurosci. Lett. 52: 253-258.

Nowak, L., P. Bregestovski, P. Ascher, A. Herbert, and A. Prochiantz (1984) Magnesium gates glutamate-activated channels in mouse central neurones. Nature 307: 462-465.

Olverman, J. J., A. W. Jones, and J. C. Watkins (1984) L-Giutamate has 
higher affinity than other amino acids for $\left.\mathrm{D}-{ }^{3} \mathrm{H} H\right]-\mathrm{AP5}$ binding sites in rat brain membranes. Nature 307: 460-462.

Ottersen, O. P. (1982) Connections of the amygdala of the rat. IV. Corticoamygdaloid connections as studied with axonal transport of horseradish peroxidase. J. Comp. Neurol. 205: 30-48.

Paxinos, G., and C. Watson (1982) The Rat Brain in Stereotaxic Coordinates, Academic Press, Inc., New York

Perkins, M., and T. Stone (1983) Pharmacology and regional variations of quinolinic acid-evoked excitation in the rat central nervous system. J. Pharmacol. Exp. Ther. 226: 551-557.

Potashner, S. J. (1983) Uptake and release of D-aspartate in the guinea pig cochlear nucleus. J. Neurochem. 41: 1094-1101.

Pumain, R., and U. Heinemann (1981) Extracellular calcium and potassium changes in mammalian neocortex. In Amino Acid Neurotransmitters, F. V. DeFeudis and P. Mandel, eds., pp. 53-58, Raven Press, New York.

Pumain, R., I. Kurcewicz, J. Louvel, and U. Heinemann (1984) Electrophysiological evidence for a differential localization of excitatory amino acid receptors in the rat neocortex. Neurosci. Lett. (Suppl.) 18: S433.

Rainbow, T. C., C. M. Wicczorck, and S. Halpain (1984) Quantitative auto radiography of binding sites for $\left[{ }^{3} \mathrm{H}\right]$-AMPA, a structural analogue of glutamic acid. Brain Res. 309: 173-177.

Scatchard, G. (1949) The allraclion of proleins for small molecules and ions Ann. N. Y. Acad. Sci. 51: 660-672.

Sharif, N. A., and P. J. Roberts (1981) L-Aspartate binding sites in rat cerebellum: A comparison of the binding of $\mathrm{L}-\left[{ }^{3} \mathrm{H}\right]$-aspartate and $L-\left[{ }^{3} \mathrm{H}\right]$ glutamate to synaptic membranes. Brain Res. 211:293-303.

Simon, J. R., J. F. Contrera, and M. J. Kuhar (1976) Binding of $\left[{ }^{3} \mathrm{H}\right]-$ kainic acid, an analogue of L-glutamate to brain membranes. J. Neurochem. 26 : $141-147$.

Simon, R. P., J. H. Swan, T. Griffiths, and B. S. Meldrum (1984) Blockade of
$N$-methyl-D-aspartate receptors may protect against ischemic damage in the brain. Science 226: 850-852.

Thomson, A. M., D. C. West, and D. Lodge (1985) An N-methylaspartate receptor-mediated synapse in rat cerebral cortex: $A$ site of action of ketamine? Nature 313: 479-481.

Unnerstall, J. R., and J. K. Wamsley (1983) Autoradiographic localization of high-affinity $\left[{ }^{3} \mathrm{H}\right]$-kainic acid binding sites in the rat forebrain. Eur. J. Pharmacol. 86: 361-371.

Unnerstall, J. R., D. L. Neihoff, M. J. Kuhar, and J. M. Palacios (1982) Quantitative receptor autoradiography using $\left[{ }^{3} \mathrm{H}\right]$-Ultrofilm: Application to multiple benzodiazepine receptors. J. Neurosci. Methods 6: 59-73.

Vogt, B. A., D. L. Rosene, and A. Peters (1981) Synaptic termination of thalamic and collosal afferents in cingulate cortex of the rat. J. Comp. Neurol. 201: 265-283.

Walters, R. J., and M. W. Berns (1981) Computer-enhanced video microscopy: Digitally processed microscopic images can be produced in real time. Proc. Natl. Acad. Sci. U. S. A. 78: 6927-6931.

Waniewski, R. A., and D. L. Martin (1983) Selective inhibition of glial versus ncuronal uptakc of $\mathrm{L}$ glutamic acid by SITS. Brain Res. 268: 390-394.

Waniewski, R. A., and D. L. Martin (1984) Characterization of L-glutamic acid transport by glioma cells in culture: Evidence for sodium-independent, chluride-deperident high affinity influx. J. Neurosci. 4: 2237-2246.

Watkins, J. C., and R. H. Evans (1981) Excitatory amino acid transmitters. Annu. Rev. Pharmacol. Toxicol. 21: 165-204.

Wigstrom, H., and B. Gustafsson (1984) A possible correlate of the postsyn aptic condition for long-lasting potentiation in the guinea pig hippocampus in vitro. Neurosci. Lett. 44: 327-332.

Yao, D., D. T. Monaghan, A. H. Ganong, E. W. Harris, and C. W. Cotman (1984) NMDA receptors in the rat brain. I. Subcellular and anatomical distribution. Soc. Neurosci. Abstr. 10: 419. 